\title{
As recomendações das comissões da verdade no Brasil sobre os arquivos da ditadura militar (1964- 1985): uma análise dos relatórios finais
}

\author{
Mônica Tenaglia \\ Doutoranda; Universidade de Brasília, Brasília, DF, Brasil; \\ motenaglia@hotmail.com \\ Georgete Medleg Rodrigues \\ Doutora; Universidade de Brasília, Brasília, DF, Brasil; \\ medleg.georgete@gmail.com
}

\begin{abstract}
Resumo: Arquivos são importantes fontes de informação e de prova nas investigações sobre graves violações de direitos humanos. O objetivo deste artigo é analisar as recomendações das comissões da verdade no Brasil sobre os arquivos da ditadura militar (1964-1985). A partir de levantamento (survey) realizado na internet e no Relatório Final da Comissão Nacional da Verdade, foram mapeadas todas as comissões da verdade criadas no Brasil desde 2012, e selecionados para o estudo os dez relatórios finais que contêm recomendações decorrentes dos problemas encontrados pelas comissões ao acessar os arquivos e sistematizar os tipos de recomendações. Os resultados evidenciaram que as comissões da verdade enfrentaram obstáculos de diversas ordens referentes ao acesso aos arquivos, nas suas dimensões física, intelectual e legal. $\mathrm{O}$ artigo conclui que os obstáculos de acesso apontados nos relatórios decorrem não apenas dos produtores dos arquivos da repressão, mas da ineficácia da gestão documental e da aplicação da lei de acesso à informação.
\end{abstract}

Palavras-chave: Ditadura Militar Brasileira. Comissões da Verdade. Acesso. Acesso físico. Acesso intelectual. Acesso legal. Arquivos Públicos. Documentos Arquivísticos.

\section{INTRODUÇÃO}

Semanas antes da publicação do relatório final da Comissão Nacional da Verdade (CNV), o seu então coordenador, Pedro Dallari, concedeu uma entrevista ao programa "Poder e Política", do UOL, sobre o andamento dos trabalhos da comissão. Quando questionado sobre a relação da CNV com as Forças Armadas, Dallari respondeu: 
Uma relação difícil. Por quê? Porque desde o começo ficou claro que, embora as Forças Armadas não fossem se opor à Comissão Nacional da Verdade, até porque é órgão de Estado, que a disposição para uma colaboração efetiva não seria grande. [...] tivemos dificuldades na obtenção de documentos, por exemplo. Houve documentos que só foram entregues a nós agora, já no final da atividade de apuração da Comissão. E há aquela situação que, para nós não está suficientemente comprovada, em que as Forças Armadas alegam que um grande número de documentos foi destruído, e nós não temos nenhuma evidência dessa destruição e os documentos não aparecem (DALLARI, 2016, doc. não paginado).

De fato, a falta de colaboração das Forças Armadas impactou diretamente nos resultados das investigações da $\mathrm{CNV}$ e foi mencionada no seu Relatório Final.

No exercício de suas atribuições, as comissões da verdade estaduais, municipais, universitárias e setoriais também enfrentaram inúmeros desafios, no contexto de obtenção de documentos produzidos pelos órgãos de informação e repressão das Forças Armadas e pelos órgãos da burocracia estatal utilizados por eles para a perpetração de graves violações de direitos humanos.

Diante dessa constatação, pareceu pertinente indagar: quais foram as recomendações feitas pelas comissões da verdade em relação aos arquivos como fonte de informação para as suas investigações?

Este artigo é parte de uma tese de doutorado em andamento no âmbito da Ciência da Informação, que tem como objetivo analisar a relação entre os obstáculos encontrados pelas comissões da verdade quanto ao acesso aos arquivos da ditadura militar de 1964, e os resultados das investigações expressos nos relatórios finais das comissões. Este estudo justifica-se pela relevância das investigações sobre as graves violações de direitos humanos cometidas pelo Estado brasileiro e devido à escassa literatura sobre as comissões da verdade e gestão dos arquivos da ditadura militar no campo da Ciência da Informação ${ }^{1}$. Para realizá-lo, utilizou-se do método de levantamento (survey) de informações nas páginas da internet, a fim de identificar todas as comissões da verdade criadas desde 2012 e que investigaram crimes cometidos pelo aparato repressivo da ditadura militar brasileira. Simultaneamente, utilizamos a lista de comissões da verdade apresentada no relatório final da CNV. Dentre essas comissões, 
foram selecionadas aquelas que apresentaram e disponibilizaram seus relatórios finais com recomendações referentes aos arquivos.

O artigo inicia-se com uma breve exposição da relação dos arquivos com os trabalhos das comissões da verdade, expondo sua importância às investigações sobre graves violações de direitos humanos. Na seção seguinte, apresentamos os procedimentos metodológicos e os resultados encontrados. Por fim, nossas reflexões finais.

\section{AS COMISSÕES DA VERDADE E A RELAÇÃO COM OS} ARQUIVOS: uma breve trajetória

Comissões da Verdade estão relacionadas a um conjunto de mecanismos utilizados no campo da justiça de transição, termo criado nas últimas décadas para designar uma área de pesquisa e de prática política em sociedades pósguerra ou pós-conflito, com a ocorrência de violações de direitos humanos em grande escala. Segundo Van Zyl (2011, p. 32), a justiça transicional possui cinco eixos orientadores que se referem a "[...] processar os perpetradores, revelar a verdade sobre crimes passados, fornecer reparações às vítimas, reformar as instituições perpetradoras de abuso e promover a reconciliação [...]”".

Nesse sentido, as comissões da verdade atuam como instrumentos nãojudiciais, oficializados pelo próprio Estado, com o propósito de buscar e investigar determinado período da história de um país. De acordo com Hayner, uma comissão da verdade:

(1) está focada no passado, e não nos eventos em curso; (2) investiga um padrão de eventos que ocorreu durante um período de tempo; (3) se envolve direta e amplamente com a população afetada, reunindo informações sobre suas experiências; (4) é um órgão temporário, com o objetivo de concluir com um relatório final; e (5) é oficialmente autorizado ou habilitado pelo Estado investigado (HAYNER, 2011, p.11-12).

Conhecida como a primeira comissão da verdade, a Comissão de Inquérito sobre o Desaparecimento de Pessoas foi estabelecida em Uganda, em 1974, pelo então presidente General Idi Amin Dada, após grande pressão popular para que fossem investigadas as denúncias sobre desaparecimentos 
ocorridos nos primeiros anos de seu governo (UNITED STATES INSTITUTE OF PEACE, 1974). Desde então, mais de quarenta comissões foram criadas mundialmente, sendo mais da metade delas criadas nos últimos dez anos (HAYNER, 2011).

Estabelecida após as eleições presidenciais de 1994, a Comissão da Verdade e Reconciliação da África do Sul (1996-1998), teve como propósito investigar as graves violações de direitos humanos cometidas pelo Estado e pelos movimentos de libertação, ocorridas durante o regime de Apartheid, que vigorou naquele país de 1948 a 1994. Durante suas atividades, a comissão coletou 21.000 depoimentos de vítimas e testemunhas, 2.000 deles realizados em audiências públicas (HAYNER 2011). Grande parte das investigações baseou-se em depoimentos, pois milhares de documentos haviam sido destruídos. A comissão descobriu que essa destruição ocorreu em grande escala durante os anos de 1990, e que alguns órgãos governamentais continuaram destruindo documentos até o final de 1996, dois anos depois da instauração do novo regime democrático na presidência de Nelson Mandela, e um ano após o funcionamento da comissão da verdade (HAYNER, 2011).

No Brasil, as recomendações para a criação da CNV foram determinadas na $11^{\mathrm{a}}$ Conferência Nacional de Direitos Humanos, realizada em Brasília, em 2009, e incorporadas ao Programa Nacional de Direitos Humanos (PNDH-3). Este incluiu, pela primeira vez, o Direito à Memória e à Verdade como um dos eixos orientadores do programa (BRASIL, 2010).

A CNV foi criada por meio da Lei $\mathrm{n}^{\circ} 12.528 / 2011$ e oficialmente instalada em 16 de maio de 2012. As atividades desenvolvidas pela comissão buscaram atender à finalidade estabelecida no artigo $1^{\circ}$ da lei:

Art. $1^{\circ}[\ldots]$ examinar e esclarecer as graves violações de direitos humanos praticadas no período fixado no artigo $8^{\circ}$ do Ato das Disposições Constitucionais Transitórias ${ }^{2}$, a fim de efetivar o direito à memória e à verdade e promover a reconciliação nacional (BRASIL, 2011b, doc. não paginado).

Paralelamente à aprovação da lei que criou a CNV, foi aprovada a Lei ${ }^{\circ}$ 12.527/2011, denominada Lei de Acesso à Informação (LAI), cujo objetivo é 
regulamentar o acesso às informações públicas e o direito à informação, previstos na Constituição Federal de 1988, e garantir maior transparência à administração pública (BRASIL, 2011a). Ela também determina que informações ou documentos que versem sobre violações de direitos humanos pelo Estado não sejam objetos de restrição de acesso ou destruição, conforme Art. 21. Portanto, a criação da LAI foi determinante para os trabalhos da CNV. Além disso, a aprovação simultânea das duas leis buscou a efetivação do direito à verdade e à memória preconizado no PNDH-3.

As atividades da CNV duraram quase três anos e coletaram 1.116 depoimentos, sendo 483 em audiências públicas e 633 em depoimentos reservados (BRASIL, 2014). Além dos depoimentos, grande parte de sua investigação foi baseada em análise documental. A CNV se beneficiou de investigações realizadas anteriormente à sua criação pelas iniciativas institucionais e da sociedade civil, em especial da Comissão Especial sobre Mortos e Desaparecidos Políticos (CEMDP) e da Comissão de Anistia. (BRASIL, 2014). Parte da pesquisa também se concentrou nos acervos dos extintos Conselho de Segurança Nacional (CSN), Comissão Geral de Investigações (CGI) e Serviço Nacional de Informações (SNI), que estavam sob custódia da Agência Brasileira de Inteligência (ABIN) e que foram transferidos para a sede do Arquivo Nacional, por determinação presidencial, em 2005. (BRASIL, 2014). A CNV também pôde utilizar os acervos das polícias políticas, recolhidos pelos arquivos públicos após decretos estaduais, especialmente durante os anos 1990 (QUADRILÁTERO, 1998).

Os trabalhos da $\mathrm{CNV}$ foram registrados em um relatório final dividido em três volumes e cinco partes. Toda a documentação levantada e produzida durante a vigência da CNV foi transferida ao Arquivo Nacional e incorporada ao Centro de Referência das Lutas Políticas no Brasil (1964-1985) - Memórias Reveladas, criado em 2009.

No Relatório Final, a CNV afirma que não pôde concluir que a integralidade da documentação produzida pelo regime militar estivesse recolhida e disponibilizada nos arquivos públicos, mesmo com a existência de mais de 20 milhões de páginas de documentos produzidos nesse período e sob 
custódia do Arquivo Nacional (BRASIL, 2014). Os motivos para esse ceticismo serão explicitados na recomendação n. 51 do Relatório final da $\mathrm{CNV}$, como veremos a seguir. Ao mesmo tempo, no item 5 do conjunto de conclusões apresentado no Relatório Final, a CNV afirma que apesar dos obstáculos ao acesso foi possível chegar a algumas conclusões a partir de documentos cuja existência vinha sendo sistematicamente negada pelas Forças Armadas, por exemplo:

5. No âmbito desse quadro de graves violações de direitos humanos, a CNV teve condições de confirmar 434 mortes e desaparecimentos de vítimas do regime militar, que se encontram identificados de forma individualizada no Volume III deste Relatório, sendo 191 os mortos, 210 os desaparecidos e 33 os desaparecidos cujos corpos tiveram seu paradeiro posteriormente localizado, um deles no curso do trabalho da CNV. Esses números certamente não correspondem ao total de mortos e desaparecidos, mas apenas ao de casos cuja comprovação foi possível em função do trabalho realizado, apesar dos obstáculos encontrados na investigação, em especial a falta de acesso à documentação produzida pelas Forças Armadas, oficialmente dada como destruída (BRASIL, 2014, p. 963, grifo nosso).

Como resultado, a CNV apresenta os itens 50 e 51 na Recomendação $\mathrm{n}^{\circ}$. 29, os quais versam sobre o prosseguimento e fortalecimento da política de localização e abertura dos arquivos da ditadura militar, sugerindo:

50. O processo de localização e abertura dos arquivos do período do regime militar, que teve grande evolução com a atuação da $\mathrm{CNV}$, deverá ter prosseguimento. Os acervos das Forças Armadas, incluindo aqueles de seus centros de informação - Centro de Informações do Exército (CIE), Centro de Informações da Marinha (Cenimar) e Centro de Informações de Segurança da Aeronáutica (Cisa) -, bem como do Centro de Informações do Exterior (Ciex), que funcionou no Ministério das Relações Exteriores (MRE), deverão ser integrados em uma plataforma única em todo o país, que abranja toda a documentação dos órgãos do Sistema Nacional de Informações e Contrainformação (Sisni). O mesmo deverá ocorrer com os arquivos de todas as Divisões de Segurança e Informações (DSI) e Assessorias de Segurança e Informações (ASI) instituídas pela ditadura militar nos órgãos do governo federal, com vinculação ao Serviço Nacional de Informações (SNI).

51. No âmbito dos estados da Federação, deverá se proceder à localização e abertura dos arquivos dos órgãos vinculados à repressão política, em especial os acervos dos departamentos ou delegacias de ordem política e social (DOPS), promovendo seu recolhimento e tratamento técnico nos arquivos públicos e sua disponibilização no banco de dados do Arquivo Nacional. Esse banco de dados, por sua vez, deve ser ampliado e aperfeiçoado por meio, respectivamente, da incorporação de cópias digitais dos 
acervos documentais e orais ainda em posse do poder público e pela instalação de recursos tecnológicos destinados à potencialização das ferramentas de pesquisa e à universalização do acesso, inclusive com a disponibilização dos acervos na internet (BRASIL, 2014, p. 975).

A instituição da CNV foi acompanhada pela criação de parcerias com órgãos e entidades em todo o país, mediante a instauração de comissões da verdade estaduais, municipais, universitárias e setoriais, conforme Art. $4^{\circ}$, Inciso VII da Lei $\mathrm{n}^{\circ}$ 12.528/2011: "VII - promover parcerias com órgãos e entidades, públicos ou privados, nacionais ou internacionais, para o intercâmbio de informações, dados e documentos [...]" (BRASIL, 2011b, doc. não paginado).

Para formalizar essas parcerias, a CNV firmou acordos de cooperação técnica. Ao término dos trabalhos da CNV, haviam sido assinados 43 acordos de cooperação, conforme o Relatório Final (BRASIL, 2014).

As comissões da verdade parceiras tiveram mandato independente da $\mathrm{CNV}$; muitas delas continuaram suas atividades após o encerramento dos trabalhos e outras comissões da verdade foram criadas depois desse período. A CNV procurou fomentar a criação das comissões da verdade no país para que suas atividades auxiliassem nas investigações da CNV, além da possibilidade de investigar instituições e grupos sociais específicos, possivelmente não incluídos no escopo na CNV.

Os resultados das investigações das comissões da verdade são apresentados em relatórios finais, que incluem os registros das experiências resultantes de suas atividades. A partir desses relatórios, pretendemos analisar as recomendações produzidas pelas comissões da verdade no âmbito dos arquivos da ditadura militar, os quais resultaram da interação entre ambos. As recomendações são analisadas na seção a seguir.

\section{RESULTADOS}

Com o intuito de identificar os relatórios finais das comissões da verdade parceiras e que contêm recomendações referentes aos arquivos da ditadura militar, mapeamos todas as comissões da verdade mencionadas no Relatório 
Final da CNV e em páginas da internet. Foi possível identificar 47 comissões da verdade instauradas por todo o território nacional. Dentre elas, 16 comissões da verdade disponibilizaram relatório final. Após análise desses relatórios, identificamos dez relatórios que contêm recomendações sobre arquivos da ditadura militar e que serão objeto do nosso estudo, conforme apresentado no Quadro 1:

Quadro 1 - Recomendações sobre os arquivos nos relatórios finais das comissões da verdade selecionadas

\begin{tabular}{|c|c|c|}
\hline $\mathrm{N}^{\circ}$. & Nome & Recomendações \\
\hline 1 & $\begin{array}{l}\text { Comissão Estadual do } \\
\text { Amapá }\end{array}$ & $\begin{array}{l}\text { - Efetivar fisicamente o Arquivo Público do Estado } \\
\text { do Amapá. }\end{array}$ \\
\hline 2 & $\begin{array}{l}\text { Comissão Estadual da } \\
\text { Verdade do Paraná }\end{array}$ & $\begin{array}{l}\text { - Abertura e livre acesso a todos os arquivos } \\
\text { referentes ao período de } 1946 / 1988 \text {. }\end{array}$ \\
\hline 3 & $\begin{array}{l}\text { Comissão Estadual da } \\
\text { Verdade do Rio de } \\
\text { Janeiro }\end{array}$ & $\begin{array}{l}\text { - Abrir os arquivos da ditadura, de modo a efetivar o } \\
\text { direito à memória e à verdade. } \\
\text { - Desenvolver, no âmbito estadual, uma política de } \\
\text { arquivos [...]. }\end{array}$ \\
\hline 4 & $\begin{array}{l}\text { Comissão da Verdade da } \\
\text { Câmara Municipal de } \\
\text { São Paulo } \\
\end{array}$ & $\begin{array}{l}\text { Ouvir o ex-Ministro da Defesa Nelson Jobim sobre } \\
\text { os arquivos queimados referentes à ditadura militar. }\end{array}$ \\
\hline 5 & $\begin{array}{l}\text { Comissão da Verdade da } \\
\text { Prefeitura de São Paulo }\end{array}$ & $\begin{array}{l}\text { - Padronizar e proceder com o correto preenchimento } \\
\text { da documentação sobre corpos inumados, exumados } \\
\text { e reinumados; } \\
\text { - Atualizar as plantas dos cemitérios municipais, } \\
\text { confeccionar mapas disponíveis para consulta e } \\
\text { determinar que qualquer alteração seja devidamente } \\
\text { registrada; } \\
\text { - Digitalizar e indexar os livros de registros dos } \\
\text { cemitérios e os documentos depositados nos arquivos } \\
\text { do Serviço Funerário do Município; } \\
\text { - Criar um sistema interligado de arquivos e } \\
\text { promover uma política permanente de organização e } \\
\text { catalogação dos acervos da Prefeitura, com apoio } \\
\text { técnico do Arquivo Histórico de São Paulo. }\end{array}$ \\
\hline 6 & $\begin{array}{c}\text { Comissão da Verdade da } \\
\text { UNB }\end{array}$ & $\begin{array}{l}\text { Localização e abertura dos acervos de órgãos de } \\
\text { segurança e informações ainda não depositados no } \\
\text { Arquivo Nacional, entre os quais os da } \\
\text { Superintendência Regional do Departamento de } \\
\text { Polícia Federal no DF, dos centros de informação das } \\
\text { Forças Armadas e os da Secretaria de Segurança } \\
\text { Pública do DF (incluindo arquivos da Polícia Civil e } \\
\text { da Polícia Militar). }\end{array}$ \\
\hline
\end{tabular}




\begin{tabular}{|c|c|c|}
\hline 7 & $\begin{array}{c}\text { Comissão da Verdade da } \\
\text { UFES }\end{array}$ & $\begin{array}{l}\text { Localização e abertura dos acervos de órgãos de } \\
\text { segurança e informação ainda não depositados no } \\
\text { Arquivo Nacional, entre os quais os da } \\
\text { Superintendência Regional do Departamento de } \\
\text { Polícia Federal no ES, dos centros de informação das } \\
\text { Forças Armadas, os da Secretaria de Segurança } \\
\text { Pública do ES e os da DSI/MEC. }\end{array}$ \\
\hline 8 & $\begin{array}{l}\text { Comissão da Verdade da } \\
\text { UFRN }\end{array}$ & $\begin{array}{l}\text { Providenciar um acondicionamento ideal para o } \\
\text { acervo de documentos do Arquivo Geral da } \\
\text { Universidade Federal do Rio Grande do Norte. }\end{array}$ \\
\hline 9 & $\begin{array}{l}\text { Comissão Camponesa } \\
\text { da Verdade }\end{array}$ & $\begin{array}{l}\text { - Que o Estado brasileiro garanta o acesso aos } \\
\text { documentos e provas que permitam comprovar as } \\
\text { violações de direitos humanos contra camponeses e } \\
\text { camponesas, bem como envide todos os esforços } \\
\text { para a abertura dos arquivos dos órgãos de repressão; } \\
\text { - Que o Estado brasileiro promova políticas públicas } \\
\text { destinadas à preservação da memória camponesa, } \\
\text { através do fomento de pesquisas voltadas à } \\
\text { recuperação, análise e registro de documentos e } \\
\text { acervos [...]. }\end{array}$ \\
\hline 10 & $\begin{array}{c}\text { Comissão da Verdade da } \\
\text { CUT }\end{array}$ & $\begin{array}{l}\text { Garantia e priorização de recursos para políticas de } \\
\text { arquivo e de memória. }\end{array}$ \\
\hline
\end{tabular}

Após apresentação das recomendações sobre os arquivos contidos nos relatórios finais das comissões da verdade, identificamos que elas envolvem, majoritariamente, a questão do acesso. Antes de analisarmos as recomendações, é interessante que abordemos, rapidamente, o conceito de acesso aos arquivos.

O glossário proposto pela Associação dos Arquivistas Australianos, apresentado no livro Keeping Archives, de Judith Ellis, define acesso como:

[...] concessão de permissão para: 1) uso dos instrumentos de pesquisa; 2) pesquisa nos arquivos ou coleções mantidas por uma instituição arquivística; 3) extração de informação dos arquivos para pesquisa ou publicação. Acesso aos arquivos pode ser restrito ou retido para prevenir dano físico ou para proteção de informação confidencial (ELLIS, 2004, p. 459-460, tradução nossa).

Já Hugh Taylor (1984), ao analisá-lo em relação ao usuário, definiu três dimensões para o acesso aos documentos arquivísticos:

a) físico - relacionado à guarda e à conservação dos documentos; 
b) intelectual - relacionado aos instrumentos de pesquisa;

c) legal - relacionado aos aspectos jurídicos que envolvem restrição e acesso.

Em definição mais recente sobre acesso aos documentos de arquivo, o Conselho Internacional de Arquivos (ICA), nas diretrizes "Princípios de Acesso aos Arquivos", afirma que o acesso é: "A disponibilidade dos arquivos para consulta como resultado da autorização legal e da existência de instrumentos de pesquisa.” (INTERNATIONAL COUNCIL ON ARCHIVES, 2012, p. 12, tradução nossa).

No caso da nossa análise, utilizaremos as três dimensões propostas por Taylor (1984) para sistematizar as recomendações feitas pelas comissões da verdade no âmbito dos arquivos.

\subsection{O acesso físico e intelectual}

As recomendações das comissões da verdade apresentadas em seus relatórios finais, considerando tanto os aspectos de acesso físico quanto intelectual dos documentos, passam pela responsabilidade do Estado, que deve proteger e preservar os arquivos, e, especialmente, pela gestão documental.

No Brasil, a lei que dispõe sobre a política nacional dos arquivos públicos e privados, a Lei $\mathrm{n}^{\circ} 8.159 / 1991$, conhecida como Lei de Arquivos, em seu Art. $1^{\circ}$, dispõe:

Art. $1^{\circ}$ - É dever do Poder Público a gestão documental e a proteção especial a documentos de arquivos, como instrumento de apoio à administração, à cultura, ao desenvolvimento científico e como elementos de prova e informação. (BRASIL, 1991, doc. não paginado).

Ainda conforme o Art. $3^{\circ}$ da lei, a gestão de documentos é

Art. $3^{\circ}-[\ldots]$ o conjunto de procedimentos e operações técnicas referentes à sua produção, tramitação, uso, avaliação e arquivamento em fase corrente e intermediária, visando a sua eliminação ou recolhimento para guarda permanente (BRASIL, 1991, doc. não paginado).

É importante ressaltar que a obrigação do Estado na gestão e disponibilização dos documentos públicos está prevista na Constituição de 1988, 
conforme o Art. 216 e parágrafo $2^{\circ}$ : “\$ $2^{\circ}$ Cabem à administração pública, na forma da lei, a gestão da documentação governamental e as providências para franquear sua consulta a quantos dela necessitem." (BRASIL, 1988, doc. não paginado).

Feitas essas observações, no conjunto de recomendações sobre o acesso aos arquivos nas dimensões física e intelectual, compreendemos que elas se referem, majoritariamente, às dificuldades ocasionadas pela ausência de gestão documental. Por isso, para que existam políticas e práticas de arquivo, é necessário, primeiramente, que exista um local adequado para a guarda dos documentos arquivísticos e sua disponibilização.

No que diz respeito aos estados brasileiros, apesar da própria Constituição Estadual do Amapá instituir como dever do Poder Público a custódia, gestão e disponibilização dos documentos, aquele estado sequer possui um arquivo público. Consequentemente, a Comissão Estadual da Verdade do Amapá recomendou a efetivação da construção do Arquivo Público do Estado do Amapá, afirmando que:

[...] sem o espaço físico qualquer política de abertura, manutenção e conservação de documentos está fadada ao fracasso, daí a necessidade urgente da construção do Arquivo Público do Estado do Amapá, hoje o único Estado da Federação que não dispõe de um prédio para funcionar o Arquivo Público (COMISSÃO ESTADUAL DA VERDADE DO AMAPÁ, 2017, p. 78).

Para enfrentar as dificuldades resultantes da ausência de gestão dos arquivos utilizados, a comissão firmou uma parceria com a Universidade Federal do Amapá (UNIFAP), que disponibilizou estagiários do curso de História para desenvolver as atividades de transcrição das oitivas, organização do acervo documental e pesquisa sobre dados biográficos (COMISSÃO ESTADUAL DA VERDADE DO AMAPÁ, 2017).

Da mesma forma, a Comissão da Verdade da UFRN citou a necessidade de um acondicionamento ideal para o acervo do Arquivo Geral da universidade, especialmente pelo fato de que os documentos dizem respeito à memória institucional e administrativa da UFRN (COMISSÃO DA VERDADE DA UFRN, 2015). Por meio da descrição dos arquivos utilizados pela comissão, é 
possível compreender que o Arquivo Geral da UFRN possui uma infraestrutura própria. No entanto, considerando a recomendação para que esse acervo seja acondicionado de forma apropriada, aparentemente o Arquivo Geral da UFRN não está atendendo às exigências de preservação adequada dos documentos.

A Comissão Estadual da Verdade do Rio de Janeiro recomendou que a gestão documental fosse estendida a outros acervos sobre a ditadura militar:

\footnotetext{
Desenvolver, no âmbito estadual, uma política de arquivos, que abarque o recolhimento ao Arquivo Público do Estado do Rio de Janeiro (APERJ) e a posterior gestão, organização, descrição, preservação (higienização, acondicionamento, climatização das áreas de depósito), digitalização e publicização dos acervos das Polícias Políticas, das Polícias Civil e Militar estaduais, dos Institutos de Medicina Legal e de outros órgãos relacionados à repressão exercida no período de 1946 a 1988 no Rio de Janeiro, garantindo recursos financeiros, materiais e humanos (COMISSÃO ESTADUAL DA VERDADE DO RIO DE JANEIRO, 2015, p. 440).
}

A comissão descreve que o GT DOPS, um dos GTs da Comissão, durante as visitas ao prédio do antigo Departamento de Ordem Política e Social do, então, Estado da Guanabara (DOPS), encontrou vasta documentação abandonada no interior do prédio, em estado avançado de deterioração, devido às inadequadas condições de armazenamento (COMISSÃO ESTADUAL DA VERDADE DO RIO DE JANEIRO, 2015).

O caso da comissão fluminense é interessante, porque a documentação dos órgãos de polícia política no estado do Rio de Janeiro foi recolhida para o Arquivo Público do Estado em 1992 (QUADRILÁTERO, 1998).

Em contrapartida, a Comissão da Verdade da Prefeitura de São Paulo, que concentrou grande parte de suas investigações nos arquivos dos Serviços Funerários do município, produziu um extenso conjunto de recomendações específicas aos diversos tipos de documentos consultados, além de recomendar a criação de um sistema interligado de arquivos da prefeitura.

A comissão recomendou que a documentação dos cemitérios municipais, bem como sobre os corpos inumados, exumados e reinumados, fosse padronizada porque "[...] é notório que a desorganização dos registros ainda contribua para o chamado 'desaparecimento burocrático' de corpos e restos 
mortais, desaparecimento este que se dá por via administrativa." (COMISSÃO DA VERDADE DA PREFEITURA DE SÃO PAULO, 2016, p. 281). Ou seja, não somente a falta de sistematização dos documentos causou dificuldades às investigações da comissão da verdade, ainda que atualmente ela traga problemas para a identificação dos corpos sepultados nos cemitérios da cidade. A comissão também recomendou que as plantas dos cemitérios municipais fossem atualizadas, assim como a digitalização dos livros de registro dos cemitérios.

Já a Comissão Camponesa da Verdade, preocupada com as graves violações de direitos humanos ocorridas no campo durante a ditadura militar, recomendou:

Que o Estado brasileiro promova políticas públicas destinadas à preservação da memória camponesa, através do fomento a pesquisas voltadas à recuperação, análise e registro de documentos e acervos, bem como a programas de investigação e publicação de materiais sobre temas correlatos ao direito à memória e à verdade, especialmente às graves violações de direitos humanos ocorridas no campo, e a inclusão de tais temáticas no currículo da Educação Básica (COMISSÃO CAMPONESA DA VERDADE, 2014, p. 988).

A Comissão da Verdade da CUT, por sua vez, recomendou que fossem implementadas políticas de arquivo que promovessem os direitos humanos e que fosse identificada e recolhida ao Arquivo Nacional toda a documentação relevante para que as graves violações de direitos humanos, sobretudo no âmbito dos trabalhadores, fossem investigadas, além dos arquivos em instituições privadas. (COMISSÃO DA VERDADE DA CUT, 2015).

Quanto à Comissão da Verdade da Câmara Municipal de São Paulo, esta destacou a questão da destruição dos arquivos da ditadura militar, sugerindo que o ex-ministro da Defesa, Nelson Jobim (mandato 2007-2011), fosse ouvido (COMISSÃO DA VERDADE DA CÂMARA MUNICIPAL DE SÃO PAULO, 2012).

\subsection{O acesso legal}

As recomendações das comissões da verdade quanto ao acesso legal aos documentos, apresentadas em seus relatórios finais, referem-se à questão da localização e abertura dos arquivos da ditadura militar. 
A Comissão Estadual da Verdade do Paraná recomendou a abertura e acesso a todos os arquivos do período de 1946 a 1988:

\begin{abstract}
Devem ser tornados públicos, para livre e facilitado acesso, todos os arquivos, papéis, relatórios, informes, documentos, fotografias, filmes e microfilmes, gravações de áudio e vídeo, e demais dados armazenados em quaisquer outros suportes físicos ou formatos técnicos, referentes ao período de 1946/1988, com a digitalização de todo o acervo documental do DOPS/PR, junto ao Arquivo Público do Estado, bem como sua disponibilização, em sítio próprio, na rede mundial de computadores (COMISSÃO ESTADUAL DA VERDADE DO PARANÁ, 2014, p. 634).
\end{abstract}

É importante ressaltar que, apesar dos arquivos do DOPS/PR terem sido transferidos ao Arquivo Público do Estado em 1991, conforme Decreto Estadual $\mathrm{n}^{\circ} 577$, a documentação ainda não havia sido digitalizada durante os trabalhos da Comissão Estadual da Verdade do Paraná, em 2014 (QUADRILÁTERO, 1998).

Por outro lado, a Comissão Estadual da Verdade do Rio de Janeiro recomendou que os arquivos dos serviços de informação da ditadura militar e das Forças Armadas fossem abertos, sugerindo:

Recolher, digitalizar e tornar públicos os acervos dos órgãos componentes do Sistema Nacional de Informações e Contrainformações (Sisni), do Sistema de Segurança Interna (Sissegin) (em especial dos DOI-CODI), das Forças Armadas (principalmente CIE, CISA e CENIMAR), das Polícias Militares e seus serviços secretos e dos institutos médicos legais (COMISSÃO ESTADUAL DA VERDADE DO RIO DE JANEIRO, 2015, p. 440).

As comissões da verdade da Universidade de Brasília (UNB) e da Universidade Federal do Espírito Santo (UFES) destacaram a necessidade de localização e abertura dos acervos pertencentes aos órgãos de segurança e informação da ditadura militar que atuam em seu próprio estado.

Igualmente, a Comissão da Verdade da UnB menciona os arquivos da Superintendência Regional do Departamento de Polícia Federal no DF, dos centros de informação das Forças Armadas e os da Secretaria de Segurança Pública do DF (incluindo arquivos da Polícia Civil e da Polícia Militar) (COMISSÃO DA VERDADE DA UNB, 2015). 
A Comissão da Verdade da UFES recomenda a abertura dos acervos da “[...] Superintendência Regional do Departamento de Polícia Federal no ES, dos centros de informação das Forças Armadas e da Secretaria de Segurança Pública do ES, e da DSI/MEC.” (COMISSÃO DA VERDADE DA UFES, 2016, p. 180).

Cabe ressaltar que, nos dois exemplos acima, apesar de os arquivos dos serviços de informação da ditadura militar terem sido transferidos da ABIN para o Arquivo Nacional, em 2005, há uma vasta documentação das agências de informação e segurança peculiares a cada estado e que ainda não foi recolhida e disponibilizada ao público.

O acesso legal aos documentos passa pela Lei de Acesso à Informação (LAI), a Lei n 12.527/2011, que regulamentou o direito de acesso à informação estabelecido na Constituição de 1988. Entretanto, como apontado nos relatórios finais das comissões da verdade analisados neste artigo, o cumprimento da lei pelos órgãos produtores de documentos arquivísticos do período da ditadura militar ainda não é uma realidade.

\section{CONSIDERAÇÕES FINAIS}

As comissões da verdade são instrumentos do processo de justiça de transição de caráter oficial e temporário, que visam examinar e esclarecer as graves violações de direitos humanos cometidas pelo Estado, a fim de efetivar o direito à memória e à verdade, e promover a reconciliação nacional.

Mundialmente, mais de 40 comissões da verdade foram instituídas desde a criação de uma comissão em Uganda, em 1974, e mais da metade dessas comissões foram estabelecidas nos últimos dez anos. No caso do Brasil, somente em 2012 é que foi instalada a Comissão Nacional da Verdade (CNV), após sua criação oficial em 2011, em paralelo com a criação da LAI. Esta última, por sua vez, é categórica no artigo 32, inciso VII, afirmando ser "conduta ilícita", suscetível de responsabilização do agente público, "destruir ou subtrair, por qualquer meio, documentos concernentes a possíveis violações de direitos humanos por parte de agentes do Estado" (BRASIL, 2011a, doc não paginado). 
Concomitantemente à criação da $\mathrm{CNV}$, comissões da verdade estaduais, municipais, universitárias e setoriais foram instaladas por todo o território nacional, para que pudessem colaborar com as investigações da CNV e examinar casos pertinentes à sua própria esfera de investigação.

Este artigo buscou identificar as recomendações produzidas pelas comissões da verdade no âmbito dos arquivos da ditadura militar, observando que as recomendações se referem à questão do acesso, agrupadas em três aspectos: acesso físico, intelectual e legal. Os obstáculos enfrentados pelas comissões da verdade no âmbito dos arquivos são frequentes e, como indicado nos relatórios das comissões selecionadas, parecem ter impedido que as comissões aprofundassem mais as investigações.

Algumas comissões da verdade produziram extensas recomendações sobre a questão dos arquivos. A título de exemplo, destacamos a Comissão Municipal da Verdade da Prefeitura de São Paulo, a Comissão Camponesa da Verdade e a Comissão da Verdade da CUT. No estágio atual da nossa pesquisa, não é possível determinar as razões que levaram essas comissões a produzirem recomendações mais detalhadas em relação aos arquivos. Duas hipóteses podem ser levantadas: a pesquisa documental teve papel importante nas investigações dessas comissões; e os membros das comissões da verdade se detiveram mais profundamente às questões dos arquivos.

No âmbito das investigações das comissões da verdade, o detentor da informação necessária é o próprio investigado e, assim como as pessoas, as instituições também relutam em produzir provas contra si mesmas. Todavia, como destacado por Rodrigues e Silva (2001), há um paradoxo nas ações do Estado: por mais secreto que seus atos sejam, suas ações são registradas em consequência da sua própria dinâmica burocrática. Por mais que o estado e seus agentes tentem destruir a produção documental, algum vestígio sobreviverá. Essa natureza paradoxal se aplica aos arquivos públicos, legitimados pelo poder público (RODRIGUES; SILVA, 2001).

Portanto, após análise das recomendações das comissões da verdade, podemos avançar a hipótese de que as dificuldades enfrentadas pelas comissões da verdade não decorrem apenas da resistência do Estado em fornecer 
informações, mas da própria ineficiência, ou ausência - por razões de diversas ordens que não vamos analisar aqui - da gestão documental nas instituições do Brasil.

\section{Referências}

BRASIL. Constituição da República Federativa do Brasil de 1988. Brasília: Presidência da República, 1988a.

BRASIL. Ato das Disposições Constitucionais Transitórias (ADCT) 1988. Brasília: Presidência da República, 1988b.

BRASIL. Lei n. 8.159, de 8 de janeiro de 1991. Dispõe sobre a política nacional de arquivos públicos e privados e dá outras providências. Diário Oficial [da] República Federativa do Brasil, Brasília, 9 jan. 1991. Retificado em 28 jan. 1991.

BRASIL. Lei n. 12.527, de 18 de novembro de 2011. Regula o acesso a informações previsto no inciso XXXIII do art. $5^{\circ}$, no inciso II do $\S 3^{\circ}$ do art. 37 e no $\S 2^{\circ}$ do art. 216 da Constituição Federal; altera a Lei no 8.112, de 11 de dezembro de 1990; revoga a Lei $n^{\circ} 11.111$, de 5 de maio de 2005, e dispositivos da Lei no 8.159, de 8 de janeiro de 1991; e dá outras providências. Diário Oficial [da] República Federativa do Brasil, Brasília, 18 nov. 2011.

BRASIL. Lei n. 12.528, de 18 de novembro de 2011. Cria a Comissão Nacional da Verdade no âmbito da Casa Civil da Presidência da República. Diário Oficial [da] República Federativa do Brasil, Brasília, 18 nov. 2011. Edição extra.

BRASIL. Comissão Nacional da Verdade. Relatório final. Brasília: CNV, 2014.

BRASIL. Programa Nacional de Direitos Humanos (PNDH-3)/Secretaria Especial dos Direitos Humanos da Presidência da República. Brasília: SEDH/PR, 2010.

COMISSÃO CAMPONESA DA VERDADE. Relatório final. Brasília, 2014.

COMISSÃO ESTADUAL DA VERDADE DO AMAPÁ. Relatório final. Macapá, 2017.

COMISSÃO ESTADUAL DA VERDADE DO PARANÁ “TERESA URBAN". Relatório final. Curitiba, 2014.

COMISSÃO ESTADUAL DA VERDADE DO RIO DE JANEIRO. Relatório final. Rio de Janeiro, 2015. 
COMISSÃO DA VERDADE DA CÂMARA MUNICIPAL DE SÃO PAULO "VLADMIR HERZOG". Relatório final. São Paulo, 2012.

COMISSÃO DA VERDADE DA CENTRAL ÚNICA DOS

TRABALHADORES (CUT). Relatório final. São Paulo, 2015.

COMISSÃO DA VERDADE DA PREFEITURA DE SÃO PAULO. Relatório final. São Paulo, 2016.

COMISSÃO DA VERDADE DA UNIVERSIDADE DE BRASÍLIA (UNB) “Anísio Teixeira”. Relatório final. Brasília, 2015.

COMISSÃO DA VERDADE DA UNIVERSIDADE FEDERAL DO ESPÍRITO SANTO (UFES). Relatório final. Vitória, 2016.

\section{COMISSÃO DA VERDADE DA UNIVERSIDADE FEDERAL DO RIO GRANDE DO NORTE (UFRN). Relatório final. Natal, 2015.}

CÔRBO, Dayo de Araújo Silva. Comissão da Verdade: os documentos e a validez do discurso. 2013. Dissertação (Mestrado em Ciência da Informação) Programa de Pós-Graduação em Ciência da Informação, Universidade Federal do Rio de Janeiro; Instituto Brasileiro de Informação em Ciência e Tecnologia. Rio de Janeiro, 2013.

CÔRBO, Dayo de Araújo Silva; LIMA, Clóvis Montenegro de. Comissão da Verdade: os documentos e a verdade. In: ENCONTRO NACIONAL DE PESQUISA EM CIÊNCIA DA INFORMAÇÃO, 14., 2013, Florianópolis. Anais... Florianópolis: UFSC, 2013.

CÔRBO, Dayo de Araújo Silva; PIMENTA, Ricardo Medeiros. O documento como objeto e elo interdisciplinar na ciência da informação: o relatório final da comissão nacional da verdade e seus efeitos sociais. In: ENCONTRO

NACIONAL DE PESQUISA EM CIÊNCIA DA INFORMAÇÃO, 17., 2016, Salvador. Anais... Salvador: UFBA, 2016.

ELLIS, Judith (Org.). Keeping archives. Victoria: Australian Society of Archivists, 2004.

HAYNER, Priscilla. Unspeakable Truths: transitional justice and the challenge of Truth Commissions. New York and London: Routledge, 2011.

INTERNATIONAL COUNCIL ON ARCHIVES. (Committee on Best Practices and Standards Working Group on Access). Principles of Access to Archives, 24 de agosto de 2012.

PIMENTA, Ricardo. A rede informacional franco-brasileira durante a ditadura militar no brasil: o caso dos arquivos da CFDT. In: ENCONTRO NACIONAL 
DE PESQUISA EM CIÊNCIA DA INFORMAÇÃO, 14., 2013, Florianópolis. Anais... Florianópolis: UFSC, 2013.

QUADRILÁTERO: revista do Arquivo Público do Distrito Federal, Brasília, v. 1, n. 1, p. 1-130, mar./ago. 1998.

RODRIGUES, Fernando. Comissão da Verdade pedirá punição para 100 militares vivos, diz Dallari. Portal UOL, Brasília, 18 nov. 2014.

TAYLOR, Hugh. Archival services and the concept of the user: a RAMP study. Paris: Unesco, 1984.

UNITED STATES INSTITUTE OF PEACE. Commission of Inquiry into the Disappearances of People in Uganda since 25 January 1971: charter. 1974.

VAN ZYL, Paul. Promovendo a justiça transicional em sociedades pósconflitos. In: REÁTEGUI, F. (Org.). Justiça de Transição: manual para a América Latina. Brasília, DF: Comissão de Anistia, Ministério da Justiça, 2011.

\title{
Brazilian truth commissions' recommendations on archives of the military dictatorship in Brazil (1964-1985): an analysis of the final reports
}

\begin{abstract}
Archives are important sources of information and evidence for the investigations of gross human rights violations. The purpose of this article is to analyze Brazilian truth commissions' recommendations on archives of the military dictatorship in Brazil (1964-1985). Based on a survey conducted on the Internet and on the National Truth Commission's Final Report, all truth commissions created in Brazil since 2012 have been mapped, and the ten final reports that contain recommendations resulting from the problems encountered by the commissions in relation to access to archives were selected for the study, and the types of recommendations were systematized. The results showed that truth commissions faced obstacles of various orders regarding access to archives, in its physical, intellectual and legal dimensions. The article concludes that the obstacles to access pointed out in the reports are a result not only from the producers of the archives, but from the inefficiency of records/archives management and of the enforcement of the law on access to information.
\end{abstract}

Keywords: Brazilian Military Dictatorship. Truth Commissions. Access. Physical access. Intellectual access. Legal access. Public Archives. Archival documents. 
Recebido: $21 / 08 / 2017$

Aceito: $13 / 11 / 2017$

${ }^{1}$ Nas Consultas no Banco de Teses e Dissertações da CAPES e no portal de eventos da ANCIB (Associação Nacional de Pesquisa e Pós-Graduação em Ciência da Informação), encontramos a dissertação de mestrado "Comissão da Verdade: os documentos e a validez do discurso" de Dayo Côrbo (CÔRBO; 2013); as comunicações apresentadas no ENANCIB: em 2013, "Comissão da verdade: os documentos e a verdade", de Dayo Côrbo e Clóvis Montenegro de Lima (CÔRBO; LIMA, 2013) e "A rede informacional franco-brasileira durante a ditadura militar no Brasil", de Ricardo Pimenta (PIMENTA, 2013); em 2016, "O documento como objeto e elo interdisciplinar na ciência da informação", de Dayo Côrbo e Ricardo Pimenta (CÔRBO; PIMENTA, 2016).

$2 \mathrm{O}$ artigo $8^{\circ}$ (ADCT) concede anistia àqueles que foram atingidos por atos de exceção, durante o período de 1946 a 1988. 